\title{
Physiopathological Mechanism and Assessment of Fetal Asphyxia
}

\author{
Panagiotis Tsikouras', Anastasia Bothou'2, Zacharoula Koukouli1, Bachar Manav1, \\ Constantinos Bouschanetzis' ${ }^{1}$, Dorelia Deuteraiou ${ }^{1}$, Xanthi Anthoulaki ${ }^{1}$, Anna Chalkidou1, \\ George Iatrakis ${ }^{3}$, Stefanos Zervoudis ${ }^{4}$, George Galazios ${ }^{1}$
}

\author{
${ }^{1}$ Department of Obstetrics and Gynaecology, Democritus University of Thrace, Komotini, Greece \\ ${ }^{2}$ Research on Female Reproduction, Democritus University of Thrace, Komotini, Greece \\ ${ }^{3}$ TEI Technical University of Athens, Athens, Greece \\ ${ }^{4}$ Rea Hospital, Athens, Greece \\ Email: ptsikour@med.duth.gr
}

How to cite this paper: Tsikouras, P., Bothou, A., Koukouli, Z., Manav, B., Bouschanetzis, C., Deuteraiou, D., Anthoulaki, X., Chalkidou, A., Iatrakis, G., Zervoudis, S. and Galazios, G. (2017) Physiopathological Mechanism and Assessment of Fetal Asphyxia. Open Journal of Obstetrics and Gynecology, 7, 617-622.

https://doi.org/10.4236/ojog.2017.76064

Received: April 28, 2017

Accepted: June 3, 2017

Published: June 6, 2017

Copyright (c) 2017 by authors and Scientific Research Publishing Inc. This work is licensed under the Creative Commons Attribution International License (CC BY 4.0)

http://creativecommons.org/licenses/by/4.0/

\begin{abstract}
Treatment and outcome of childbirth depend on the acidobasic balance of the fetal blood related to the oxygen and carbon dioxide level. Hypoxemia could lead to asphyxia that is why fetal monitoring and biochemical parameters assessment are mandatory. Although there are compensatory mechanisms that temporarily protect the fetus, there are also other factors that interfere with the oxygenation of the fetus and determine the development of the fetus and the newborn. Actually, the level of the oxygen, the carbon dioxide, the acidobasic balance and the $\mathrm{pH}$ are the cornerstones of the well-being of the fetus.
\end{abstract}

\section{Keywords}

Hypoxia, Asphyxia, Fetal pH

\section{Introduction}

Successful treatment and outcome of childbirth depend mainly on the assessment of the good status of the fetus. This could be achieved by using modern biochemical and biophysical methods of monitoring. With these methods we try to determine directly or indirectly the degree of oxygenation of the fetus [1].

\section{Perinatal Asphyxia}

\subsection{Terminology}

Oxygen partial pressure means the amount of oxygen dissolved in the plasma which is about $2 \%$ of the total quantity of oxygen contained in the blood. By determining the oxygen in the blood, taken from the fetal head at childbirth, the 
magnitude of the partial oxygen pressure is calculated.

Oxygen Saturation is the percentage of oxygen-associated to hemoglobin in the fetus and represents $60 \%-87 \%$.

Blood oxygen content refers to oxygen dissolved in the plasma bounded to hemoglobin. By this way, a determined provision of oxygen in the tissues is achieved.

Blood oxygen capacity is the maximum blood capacity to carry oxygen, when hemoglobin is fully saturated.

Volume of oxygen transferred to the tissues based on the quantity of the oxygen content in the blood and on the cardiac function, particularly on the volume of the pulse.

The $\mathrm{O}_{2}$ transfer from the atmosphere begins from the maternal lungs and ends up to fetal tissues. This $\mathrm{O}_{2}$ transfer from the maternal to fetal circulation is done by passive diffusion, given that partial pressure of $\mathrm{O}_{2}$ in fetuses is significantly lower than maternal. Basically, the fetus lives and develops in an environment that is hypoxic regarding the maternal environment. However, despite the normal low partial pressure of $\mathrm{O}_{2}(20-30 \mathrm{~mm} \mathrm{Hg})$, fetal tissues have adequate amount of $\mathrm{O}_{2}$ to cover their needs. This is accomplished through the increased transfer ability of $\mathrm{O}_{2}$ in fetal blood and is due to increased fetal hemoglobin levels [2].

If the gas interchange is disturbed or the $\mathrm{O}_{2}$ supply is suspended, the fetal blood $\mathrm{O}_{2}$ reserves act as safeguards. Therefore, in the same time some more mechanisms that reduce further intensive procedures are activated as well and the fetal oxygenation is protected. Such mechanisms are the cardiac supply changes, the increase of blood capacity in $\mathrm{O}_{2}$, reduced movements and fetal development and generally the modification of all fetal functions. When the $\mathrm{O}_{2}$ supply to the fetus is significantly reduced, the anaerobic metabolism is activated, resulting in increased lactic acid production and decrease in fetal arterial blood $\mathrm{O}_{2}$ saturation. The base excess follows and the fetus develops metabolic acidosis that reduces the affinity of fetal $\mathrm{Hb}$ to $\mathrm{O}_{2}$ and causes further $\mathrm{SpO}_{2}$ reduction. The severe and prolonged decrease of $\mathrm{O}_{2}$ supply to brain has direct correlation with brain perfusion [3].

In term fetuses normal blood flow in brain is estimated to be $100 \mathrm{ml} / \mathrm{min} /$ $100 \mathrm{gr}$ of tissue. When this tempo is reduced to levels lower than $50 \mathrm{ml} / \mathrm{min} /$ $100 \mathrm{gr}$ of tissue, then the protein synthesis in brain is significantly affected, whereas in levels less than $15-20 \mathrm{ml} / \mathrm{min} / 100 \mathrm{gr}$ of tissue, the ATP synthesis is disturbed, resulting in damages in neurons' electric activity. If this low blood flow persists for a long time or is reduced further to levels less than $10 \mathrm{ml} / \mathrm{min} / 100 \mathrm{gr}$ of tissue, then the brain damage becomes permanent.

\subsection{Physiopathology-Perinatal Asphyxia}

During perinatal period, asphyxia is strictly defined as the combination of oxygen deprivation and acidosis with a decline of organ functions.

Asphyxia is the result of events originally associated with hypoxemia and then 
with hypoxia. Generally, the term hypoxia means the significant reduce of $\mathrm{O}_{2}$ in inhaling air and consequently in tissues. In hypoxia, the $\mathrm{O}_{2}$ supply is inadequate for the tissues' oxygen requirements. As a result, the aerobic metabolism is completed by the anaerobic in order to maintain the energy balance. If hypoxia is prolonged, the anaerobic metabolism produces lactic acid and the hydrogen ions are increased. It is understood that oxygen deficiency is accompanied by acidosis and as a result the energy balance cannot be maintained anymore. Organ function reduction follows, with the risk of permanent tissue damages. This situation is characterized as asphyxia [4].

Hypoxemia is expressed by reduced oxygen blood pressure and oxygen content and hypoxia with reduced oxygen supply to tissues. Fetal distress-stress and acidosis can be diagnosed with a relevant accuracy by laboratory methods. However, sometimes the distinction of the above mentioned conditions is not easy. Consequently, they are usually evaluated as a single entity. The earliest indication of fetal distress is the intrapartum decrease of fetal heart rate. Other classic clinical indications are colored amniotic fluid and fetal tachycardia [5].

The grade of fetal distress-hypoxia-acidosis development depends on the gravity of the etiological factor and the fetal condition. The term fetal distress concerns primarily the fetus, because it can develop in fetuses with poor counter-balancing mechanisms after the effect of natural procedures, like normal labor. However, frequent labor pain that causes cardiotocography deteriorations does not lead to fetal distress-acidosis in fetuses with sufficient counter-balancing mechanisms. Therefore, situations that cause severe hypoxia, followed by acidosis, result in cardiotocography late decelerations and in decreased $\mathrm{pH}$ levels in blood sampling from the fetal scalp [6] [7] [8].

For many years, perinatal asphyxia has been diagnosed on the basis of Apgar Score clinical criteria. Although a serious hypoxic fetus is expected to have low Apgar Score after delivery, asphyxia is not the only cause. Other possible causes that lead to asphyxia are prematurity, infection, trauma and congenital abnormalities of the fetus [5].

The diagnosis of perinatal asphyxia requires the presence of the following characteristics: low Apgar Score, metabolic acidosis and neonatal complications. However, the common use of the term perinatal asphyxia should be avoided. Obviously, the incidence, the description and the time of acidosis should be determined in order to avoid confusion in the use of this term.

Neonatal encephalopathy is thought to be the result of perinatal asphyxia. For the diagnosis of intrauterine asphyxia, a combination of the following factors: metabolic acidosis, low Apgar Score and neonatal complications are necessary [9].

The placenta is like a gas exchange device for the fetus. Oxygen diffuses from maternal to the fetal blood through the placenta and is transferred to the fetus through the umbilical vein.

Un-oxygenated blood with metabolic waste and carbon dioxide goes back to the placenta through the two umbilical arteries. Therefore, the umbilical vein blood expresses the placental acid-base condition, while the blood of the umbili- 
cal arteries reflects the acid-base balance of the fetus.

Fetal oxygen supply is determined by the following factors: 1) the level and type of hemoglobin; 2) the blood content in $\mathrm{O}_{2}\left(\mathrm{pO}_{2}\right.$ and $\left.\mathrm{SpO}_{2}\right)$; and 3) the blood flow [10].

\section{Fetus Oxygenation Status Evaluation}

\subsection{Pathological Oxygenation of the Fetus}

During pregnancy and childbirth there exist some factors to lead to reduction in oxygen supply to the fetus:

1) Uterus: General conditions, such as hypotension, ischemia or compression of the mother's aorta, may cause in a reduction in blood flow to the uterus.

2) Maternal causes: Heart's diseases that cause pulse volume reduction and hypotension may cause a reduction in blood flow to the uterus. In addition, hemoglobinopathies, respiratory diseases (e.g. asthma), the immune system diseases (e.g. systemic lupus erythematosus) and poorly regulated gestational diabetes mellitus may be responsible for reduced blood flow in the uterus [11].

3) Umbilical cord: The prolapse, compression and wrapping of the umbilical cord around the fetus can create conditions of reduced blood flow to it, resulting in its under-oxygenation.

4) Placenta: Placental deficiency e.g. in prolonged gestation, results in limiting the functional surface of the placenta and in the significant reduction of gas exchange and the supply of the fetus to oxygen. Although normal fetal $\mathrm{pO}_{2}(20-25$ $\mathrm{mm} \mathrm{Hg}$ ) is lower than that of an adult, the necessity of extra tissue oxygenation in some cases is covered by the increase of cardiac work and the increase of blood flow in systematic circulation [10]. The contribution of increased ability of oxygen transfer of fetal blood is also important. The necessity of extra oxygenation causes acidosis of glucose (main fetal energy reserve) to $\mathrm{CO}_{2}$ and $\mathrm{H}_{2} \mathrm{O}$ and additionally the production of $38 \mathrm{~mol} \mathrm{ATP/glucose}$ molecule. The $\mathrm{CO}_{2}$ is diffused easily through placenta and eliminated off maternal organism. Conditions that either cause decrease in greater blood quantities adduction to embryo-placental unit or decrease in the ability of fetal tissues' extra oxygenation, result in hypoxia-metabolic acidosis establishment with characteristic fetal reactions dependent mainly on fetal state [12].

5) The periodic delay of the contractions may cause occasional decrease in the utero-placental blood flow, resulting in decreased $\mathrm{CO}_{2}$ elimination and in respiratory acidosis. The decrease in blood flow that lasts more than usually, as it happens in cases of tetanic uterus contractions, may affect unfavorably the procedure of aerobic metabolism even in healthy fetuses. In such cases, the mechanism of anaerobic glycolysis, with the production and accumulation of pyruvate acid and lactic acid, is activated and metabolic acidosis is developed. Additionally, in cases of hypoxia, lactate dehydrogenase, that stimulates the conversion of pyruvate into lactic acid, is activated [13].

6) Fetal causes: Some infections like toxoplasma or cytomegalovirus could decrease the functional surface of the placenta and induce the sub-oxygenation of 
the fetus. Anemia caused by hemolysis in Rh-sensitized pregnant women or by embryo-fetal transfusion in monozygotic twins, reduces the fetal oxygenation [14] [15].

\subsection{Assessment of Fetal Oxygenation}

The last 40 years, the assessment of the fetus status is achieved with the cardiotocographic monitoring [16]. Urgent endometrial conditions regarding the oxygenation and mainly regarding the oxygenation of the fetus are provided by the biochemical analysis of the blood, obtained by punction of the umbilical cord or by sampling from the skin of the fetus's head or by oxymetry.

\section{Conclusion}

The time of onset, duration and intensity of under-oxygenation play a key-role in fetal development and neonatal neurological status. Although there are compensatory mechanisms that temporarily protect the fetus, there are also other factors that interfere with the oxygenation of the fetus and determine the development of the fetus and the newborn. Actually, the level of the oxygen, the carbon dioxide, the acidobasic balance and the $\mathrm{pH}$ are the cornerstones of the well-being of the fetus.

\section{References}

[1] Miller, D., Lockwood, C. and Barss, V. (2017) Intrapartum Fetal Heart Rate Assessment. Intrapartum Fetal Heart Rate Assessment.

[2] Finer, N. and Leone, T. (2009) Oxygen Saturation Monitoring for the Preterm Infant: The Evidence Basis for Current Practice. Pediatric Research, 65, 375-380. https://doi.org/10.1203/PDR.0b013e318199386a

[3] Norén, H., Luttkus, A.K., Stupin, J.H., et al. (2007) Fetal Scalp pH and ST Analysis of the Fetal ECG as an Adjunct to Cardiotocography to Predict Fetal Acidosis in Labor. A Multi-Center, Case Controlled Study. Journal of Perinatal Medicine, 35, 408-414. https://doi.org/10.1515/JPM.2007.097

[4] Low, J.A. (2013) Fetal Asphyxia: A Case Study of Translational Research. Journal of Obstetrics and Gynaecology Canada, 35, 258-262. https://doi.org/10.1016/S1701-2163(15)30998-1

[5] Martin, R., Garcia-Prats, J. and Kim, M. (2017) Overview of Neonatal Respiratory Distress: Disorders of Transition. Overview of Neonatal Respiratory Distress: Disorders of Transition.

[6] Antoine, C., Young, B.K. and Silverman, F. (1984) Simultaneous Measurement of Fetal Tissue $\mathrm{pH}$ and Transcutaneous $\mathrm{pO} 2$ during Labor. European Journal of $\mathrm{Ob}$ stetrics, Gynecology, and Reproductive Biology, 17, 69-76. https://doi.org/10.1016/0028-2243(84)90131-X

[7] Clark, S.L., Gimovsky, M.L. and Miller, F.C. (1982) Fetal Heart Rate Response to Scalp Blood Sampling. American Journal of Obstetrics and Gynecology, 144, 706708. https://doi.org/10.1016/0002-9378(82)90441-0

[8] Clark, S.L., Gimovsky, M.L. and Miller, F.C. (1984) The Scalp Stimulation Test: A Clinical Alternative to Fetal Scalp Blood Sampling. American Journal of Obstetrics and Gynecology, 148, 274-277. https://doi.org/10.1016/S0002-9378(84)80067-8 
[9] American Academy of Pediatrics, American College of Obstetricians and Gynecologists. (2003) Neonatal Encephalopathy and Cerebral Palsy: Defining the Pathogenesis and Pathophysiology. AAP, ACOG, Washington DC.

[10] Althabe Jr, O., Schwarcz, R.L., Pose, S.V., et al. (1967) Effects on Fetal Heart Rate and Fetal pO2 of Oxygen Administration to the Mother. American Journal of $\mathrm{Ob}$ stetrics and Gynecology, 98, 858-870. https://doi.org/10.1016/0002-9378(67)90205-0

[11] Omo-Aghoja, L. (2014) Maternal and Fetal Acid-Base Chemistry: A Major Determinant of Perinatal Outcome. Annals of Medical and Health Sciences Research, 4, 8-17.

[12] Honjo, S. and Yamaguchi, M. (2001) Umbilical Artery Blood Acid-Base Analysis and Fetal Heart Rate Baseline in the Second Stage of Labor. Journal of Obstetrics and Gynaecology Research, 27, 249-254.

https://doi.org/10.1111/j.1447-0756.2001.tb01265.x

[13] Khazin, A.F., Hon, E.H. and Hehre, F.W. (1971) Effects of Maternal Hyperoxia on the Fetus. I. Oxygen Tension. American Journal of Obstetrics \& Gynecology, 109, 628-637. https://doi.org/10.1016/0002-9378(71)90639-9

[14] Hutter, D., Kingdom, J. and Jaeggi, E. (2010) Causes and Mechanisms of Intrauterine Hypoxia and Its Impact on the Fetal Cardiovascular System: A Review. International Journal of Pediatrics, 2010, Article ID: 401323. https://doi.org/10.1155/2010/401323

[15] Macones, G., Ramin, S. and Barss, V. (2017) Management of Intrapartum Category I, II, and III Fetal Heart Rate Tracings. UpToDate.

[16] Romano, M., Bracale, M., Cesarelli, M., Campanile, M., Bifulco, P., De Falco, M., Sansone, M. and Di Lieto, A. (2006) Antepartum Cardiotocography: A Study of Fetal Reactivity in Frequency Domain. Computers in Biology and Medicine, 36, 619-633. https://doi.org/10.1016/j.compbiomed.2005.04.004

\section{Submit or recommend next manuscript to SCIRP and we will provide best service for you:}

Accepting pre-submission inquiries through Email, Facebook, LinkedIn, Twitter, etc. A wide selection of journals (inclusive of 9 subjects, more than 200 journals)

Providing 24-hour high-quality service

User-friendly online submission system

Fair and swift peer-review system

Efficient typesetting and proofreading procedure

Display of the result of downloads and visits, as well as the number of cited articles

Maximum dissemination of your research work

Submit your manuscript at: http://papersubmission.scirp.org/

Or contact ojog@scirp.org 